\title{
DESAIN LOGO SEBAGAI IDENTITAS VISUAL APLIKASI JELAJAH KAMPUS VIRTUAL (JEJAKATUA) UPN VETERAN JAWA TIMUR
}

\author{
Tri Lathif Mardi Suryanto ${ }^{1}$, Nur Cahyo Wibowo ${ }^{2}$, Masnuna ${ }^{3}$ \\ 1,2Sistem Informasi, Fakultas Ilmu Komputer, UPN “Veteran” Jawa Timur, \\ ${ }^{3}$ Desain Komunikasi Visual, Fakultas Arsitektur dan Desain, UPN Veteran" Jawa Timur \\ trilathif.si@upnjatim.ac.id ${ }^{1}$, nurcahyo.si@upnjatim.ac.id², masnuna.dkv@upnjatim.ac.id ${ }^{3}$
}

\begin{abstract}
Abstrak
Jelajah Kampus Virtual (Jejakatua) adalah aplikasi virtual tour kampus UPN "Veteran" Jawa Timur (UPNVJ) yang hadir sebagai media digital untuk memberikan layanan kampus yang baik dan prima. Aplikasi Jejakatua bisa diakses di website UPN "Veteran" Jatim melalui koneksi internet di mana saja dan kapan saja sehingga perlu adanya identitas visual untuk mempromosikan aplikasi Jejakatua kepada masyarakat yang membutuhkannya. Melalui perancangan logo, aplikasi Jejakatua diharapkan bisa dikenal masyarakat dan berfungsi sebagai tanda jaminan kualitas, mencegah peniruan atau pembajakan. Penelitian ini menggunakan dua tahapan yaitu tahap persiapan dan tahap penciptaan. Tahap persiapan meliputi pengumpulan data, analisis $5 \mathrm{w}+1 \mathrm{H}$, dan sintesis. Tahap penciptaan meliputi pra produksi, produksi, dan pasca produksi. Logo aplikasi Jejakatua dirancang sesuai aspek pembuatan logo yang meliputi efektivitas, teknik, warna, dan regulasi. Sehingga dapat tercipta sesuai kaidah desain dan memiliki kebaruan dan desain kekinian yang berbeda dengan logo lainnya dan mampu mencitrakan dirinya sebagai aplikasi virtual tour di lingkungan UPNVJ. Logo diimplementasikan di aplikasi Jejakatua dan media promosi seperti stationary dan merchandise. Media promosi tersebut dipublikasikan di laman resmi www.upnjatim.ac.id dan Instagram.
\end{abstract}

Kata kunci: aplikasi, jejakatua, logo, UPN, virtual tour

\begin{abstract}
Jejakatua is a virtual tour application for UPN "Veteran" East Java (UPNVJ) campus as digital media to provide excellent campus services. Jejakatua application can be accessed on the UPNVJ website through an internet connection, anywhere and anytime, so that there is a need for a visual identity to promote the Jejakatua application to the people who need it. By designing the logo of Jejakatua, it can be known to the public and serves as a sign of quality assurance, preventing imitation or piracy. This study uses two methods: The preparation phase includes data collection, analysis of $5 w+1 H$, and synthesis. The creation phase covers pre-production, production, and post-production. Jejakatua application logo is designed according to the aspects of making a logo which includes effectiveness, technique, color, and regulation so that it can be created according to design rules and has a novelty and contemporary design that is different from other logos and can image itself as a virtual tour application in the UPNVJ environment. The logo is implemented in the Jejakatua application and promotional media such as stationery and merchandise. Then the promotional media was published on the official pages of www. upnjatim.ac.id and instagram.
\end{abstract}

Keywords: application, jejakatua, logo, UPN, virtual tour 


\section{PENDAHULUAN}

Universitas Pembangunan Nasional "Veteran" Jawa Timur, disingkat UPN "Veteran" Jatim berlokasi di Surabaya merupakan salah satu Perguruan Tinggi di Indonesia yang berdiri sejak 5 Juli 1959. UPN "Veteran" Jawa Timur didirikan oleh para veteran pejuang perang kemerdekaan sebagai monumen hidup dalam mengembangkan pendidikan di Indonesia khususnya pendidikan tinggi. Sejak tanggal 6 Oktober 2014, Presiden RI Susilo Bambang Yudhoyono, menandatangani prasasti yang menandai pengesahan UPN "Veteran" Jawa Timur menjadi Perguruan Tinggi Negeri (PTN) (UPN 2018). Dengan dinobatkan menjadi PTNB menjadikan UPN "Veteran" Jatim semakin bersemangat dalam menuju cita-cita Institusi yakni menjadi Universitas Unggul Berkarater Bela Negara sesuai visi UPN "Veteran" Jatim. Dengan demikian UPN "Veteran" Jatim harus dapat memberikan layanan umum terhadap masyarakat khususnya para calon mahasiswa hingga calon mitra kerjasama dari dalam dan luar Negeri.

Kinerja kualitas layanan kampus ditentukan oleh kualitas pemberian layanan yang diberikan kepada stakeholder. Kualitas layanan dalam kampus ditentukan oleh sejauh mana kebutuhan dan harapan masyarakat dapat dipenuhi. Seberapa baik nantinya sebuah layanan berkontribusi pada kelangsungan kehidupan kampus dalam dinamika kompetisi jangka panjang (Aprillia 2018). UPN “Veteran” Jawa Timur sebagai Perguruan Tinggi Negeri Baru (PTNB) harus mengejar posisi sebagai kampus yang sejajar dengan PTN lainnya di Indonesia agar tidak ketinggalan dibidang promosi digital. Selain itu UPN "Veteran" Jawa Timur juga memiliki peluang untuk berlomba memberikan layanan informasi dan promosi digital terbaiknya yang lebih kompetitif. Pengaruh kualitas pelayanan dan nilai pelanggan dapat mempengaruhi citra Institusi (Hendrayana 2014).

Aplikasi Jelajah Kampus Virtual, disingkat menjadi Jejakatua adalah aplikasi virtual tour di lingkungan kampus UPN "Veteran" Jawa Timur yang hadir sebagai media digital untuk memberikan layanan kampus yang baik dan prima. Aplikasi Jejakatua bisa diakses di laman resmi website UPN "Veteran" Jawa Timur (https://www.upnjatim.ac.id/vtour/) melalui koneksi internet dimana saja dan kapan saja. Virtual Tour adalah simulasi dari sebuah lokasi yang sesungguhnya, umumnya terdiri oleh sequence video atau kumpulan foto (Colasante 2011). Virtual tour juga dapat menggunakan beberapa elemen multimedia lain, contohnya seperti sound effect, musik, narasi, dan teks, dan sering digunakan untuk menggambarkan varietas dari media yang berbasis video dan fotografi. Karakteristik tour merepresentasikan citra dari tempat dari objek, tata letak yang akurat, fasilitas yang tersedia, interaktivitas dan kemampuan untuk bernavigasi secara bebas di virtual.

Virtual tour menyediakan pengalaman seperti mengunjungi lokasi secara nyata dan dapat dicapai dengan menggunakan karakteristik yang realistis mewakili tempat-tempat yang akan diaktualisasikan sehingga memberikan gambaran lingkungan virtual terasa nyata dan hampir tidak bisa dibedakan serta seolah-olah dapat berjalan-jalan dengan mode virtual dengan memanfaatkan gambar panorama yang telah disesuaikan sehingga pengguna dapat merasakan pengalaman berkunjung ke UPN "Veteran" Jawa Timur secara online dan terasa realistis. Hasil dari beberapa peneliti dibidang promosi digital 
memberikan simpulan bahwa aplikasi jelajah virtual kampus berguna untuk membantu dan mempermudah masyarakat terutama calon mahasiswa baru untuk lebih mengenal lingkungan Kampus secara lebih detail. Sekaligus menjadi media promosi digital untuk meningkatkan daya tarik Kampus (Anwar 2018). Berikut gambaran aplikasi Jejakatua yang ada di website UPN "Veteran" Jawa Timur.

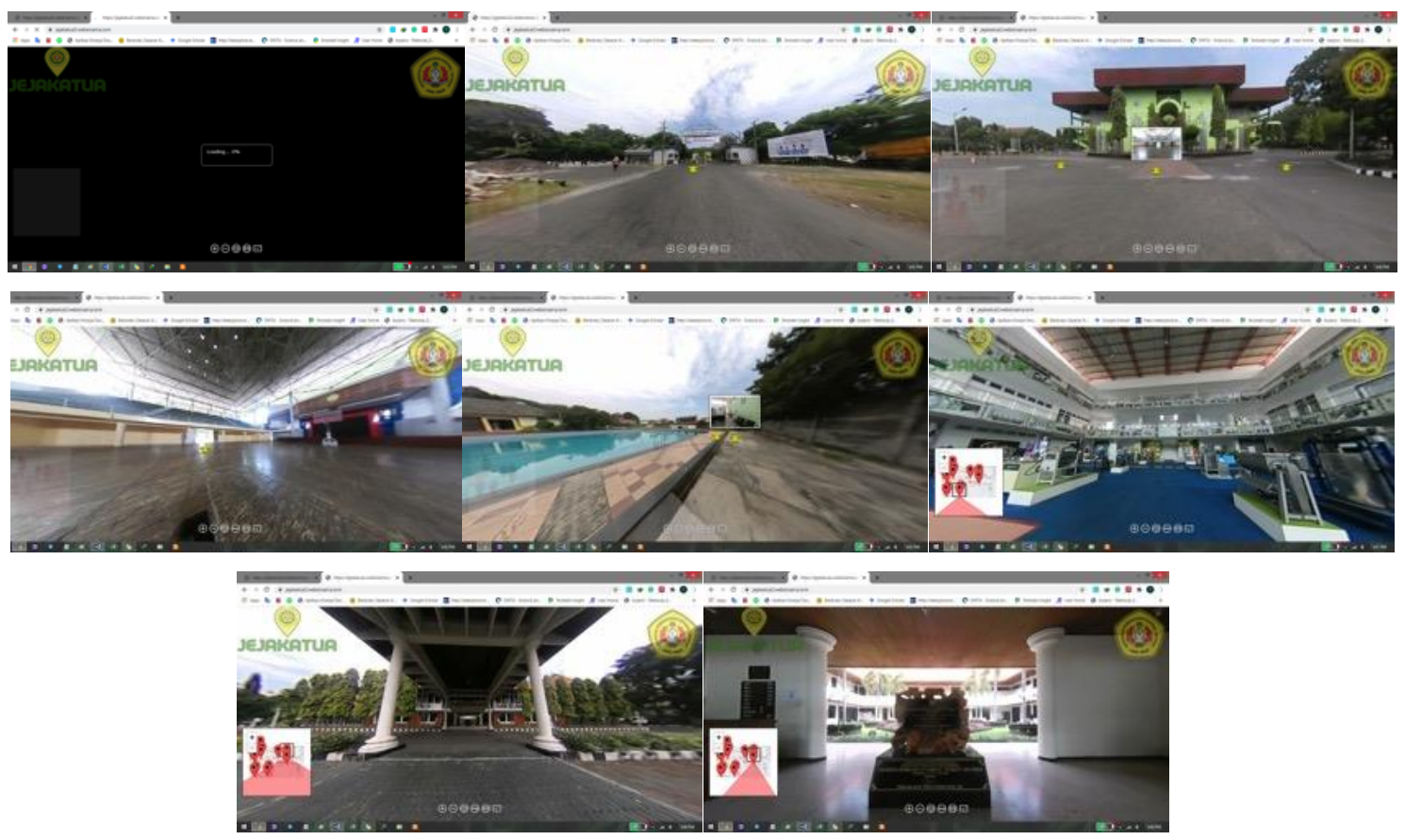

Gambar 1. Tampilan Aplikasi Jejakatua

[Sumber: https://www.upnjatim.ac.id/vtour/]

Dengan adanya aplikasi Jejakatua maka masyarakat diharapkan semakin mudah mengunjungi kampus UPN "Veteran" Jawa Timur melalui virtual tour dan memiliki beberapa manfaat seperti berikut: (1) Jaringan kampus bisa berkembang mulai dari Regional, Nasional, bahkan Internasional; (2) Calon mahasiswa baru, calon mitra, ataupun kolega dari luar kota, luar daerah atau bahkan luar negeri tentunya memiliki keingintahuan tentang gambaran kampus yang akan dipilih; (3) Jauhnya jarak yang sejalan dengan biaya sudah tidak lagi menjadi kendala untuk melihat atau menuju kampus UPN “Veteran” Jawa Timur; (4) Virtual tour menjadi solusi di era millenial seperti saat ini ditambah lagi dengan adanya pandemi COVID-19 yang mengharuskan kita untuk lebih baik di rumah dan tidak bepergian kemana-mana, sehingga aplikasi Jejakatua bisa memberikan pengalaman nyata dan kesan yang lebih mendalam bagi pihak-pihak tersebut daripada sekedar membaca data dan foto statis.

Setelah aplikasi Jejakatua diterapkan pada website resmi UPN "Veteran" Jawa Timur maka perlu adanya media yang diharapkan untuk mampu mempromosikan aplikasi Jejakatua kepada masyarakat yang membutuhkannya. Maymun \& Swasty (2018) menyebutkan bahwa untuk bisa mengenali produk yang dipasarkan, maka perlu adanya kesesuaian identitas visual dengan tema, artinya identitas visual aplikasi Jejakatua harus memliki unsur yang selaras dengan karakter Kampus, perancangan identitas visual dan 
kemasan serta melakukan promosi yang sesuai dan tepat sasaran sangat diperlukan agar masyarakat menyadari akan adanya produk (Septiningtyas \& Soewardikoen, 2018).

Media yang bisa mempromosikan aplikasi Jejakatua adalah logo sebagai identitas visual. Logo atau tanda gambar (picture mark) merupakan identitas yang dipergunakan untuk menggambarkan citra dan karakter dari suatu lembaga atau perusahaan maupun organisasi. Sementara logotype ialah tanda kata (word mark) yang merupakan nama lembaga, perusahaan, atau produk yang tampil dalam bentuk tulisan yang khusus untuk menggambarkan ciri khas secara komersial. Selain membangun citra Lembaga, identitas visual juga memiliki tujuan sebagai peningkatan minat mengunjungi sebuah lembaga (Agustin \& Putra, 2020). Logo merupakan elemen desain sangat penting dan menjadi identitas visual. Penerapan logo selalu ada dalam aplikasi identitas visual lainnya. Oleh karena itu penting untuk merencanakan logo yang dapat mencerminkan kepribadian dan jiwa sebuah brand (Oscario, 2013).

Penlitian lainnya Yusantiar \& Soewardikoen (2018) menyebutkan cara efektif untuk memunculkan identitas adalah dengan memanfaatkan unsur visual yang merangsang penglihatan. Membuat aplikasi saat ini memang mudah, dengan berbagai open software yang telah tersedia di pengembang software, namun mereka lupa bahwa logo (merk / brand) juga memegang perang penting dalam menjaga siklus hidup sebuah aplikasi. Seolah jika sudah mengenal logonya saja ada nuansa kepercayaan, keyakinan, peduli, willing, acceptance, terhadap aplikasi tersebut hanya dengan melihat logonya, seperti contoh Facebook Inc. yang telah mengakuisisi Instagram dan Whatsapp, jika melihat logo Facebook semua orang yakin bahwa produknya akan berkaitan dengan sosial media. Oleh karena itu, tujuan penelitian ini difokuskan untuk merancang logo sebagai identitas visual aplikasi Jejakatua yang diimplementasikan dalam rangkaian media dan item-item seperti stationery untuk membentuk citra sesuai dengan karakter serta identitas Jejakatua melalui identitas visual yang mampu bersaing dengan kompetitor dalam mempromosikan dan mengenalkan sebuah aplikasi dalam memberikan layanan informasi dan promosi digital agar masyarakat mengetahui dan menggunakan aplikasi Jejakatua untuk keperluan informasi keberadaan Universitas Pembangunan Nasional "Veteran" Jawa Timur.

\section{METODE PENELITIAN}

Penelitian ini menggunakan dua tahapan yaitu tahap persiapan dan tahap penciptaan. Tahap persiapan meliputi pengumpulan data, analisis data, dan sintesis. Tahap penciptaan meliputi pra produksi, produksi, dan pasca produksi (Sugiyono 2018): 


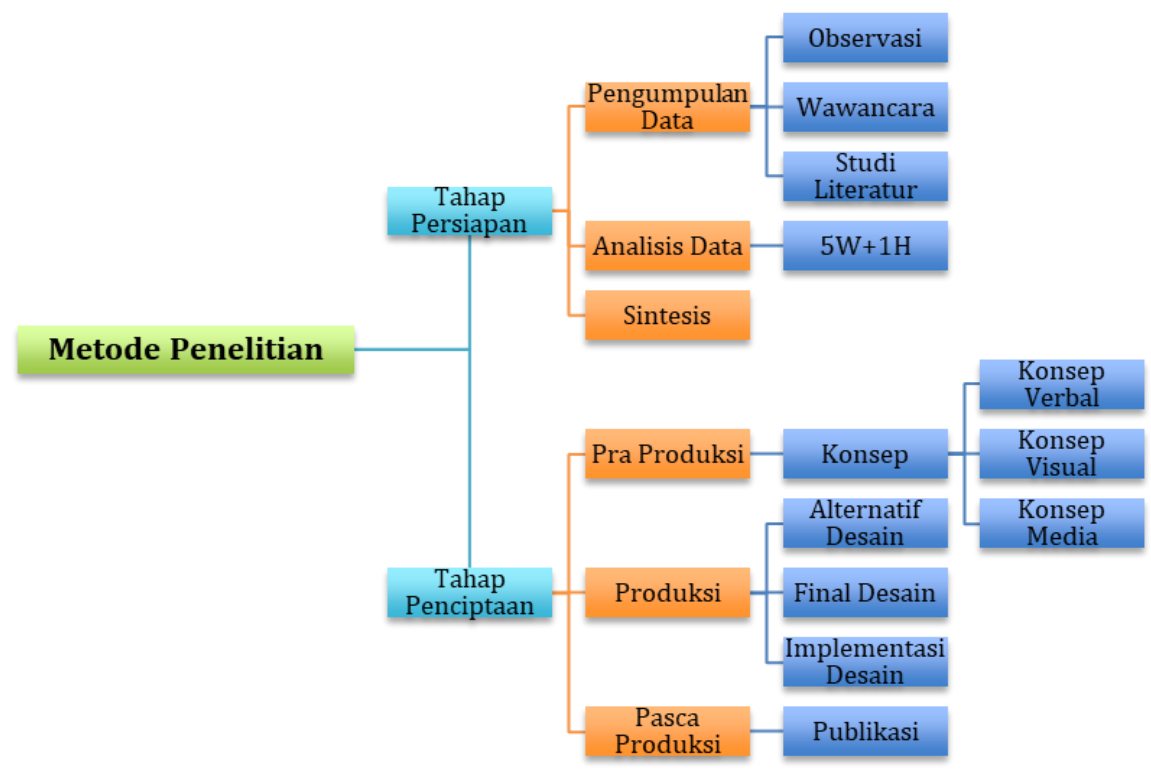

Gambar 2. Bagan Metode Penelitian.

[Sumber: Dokumentasi Tim Peneliti]

\subsection{Tahap Persiapan}

Tahap pengumpulan data menggunakan teknik observasi, wawancara, dan studi literatur. Observasi merupakan teknik pengumpulan data yang mengandalkan pengamatan untuk mengamati fenomena yang ada di lingkungan sekitar sehingga membutuhkan ketelitian dan ketajaman mata dalam melihat fenomena hingga skala terkecil. Observasi dilakukan sebagai teknik untuk mengumpulkan data primer yaitu data yang didapatkan langsung dari kampus UPN "Veteran" Jawa Timur. Tahapan ini peneliti melaksanakan kunjungan lapangan/observasi lokasi, mengamati atribut yang dipakai oleh UPN "Veteran" Jatim, baik dari bentuk dan warna gedung, model dan warna seragam karyawan, logo UPN "Veteran" Jatim, warna almamater mahasiswa, situasi dan kondisi lingkungan UPN "Veteran" Jatim, serta mengamati peserta UTBK 2020 yang bertempat di UPN "Veteran" Jatim untuk mengamati benda apa saja yang dibawa oleh peserta UTBK, hal ini untuk keperluan media promosi Aplikasi Jejakatua. Observasi tersebut dilakukan untuk mendapatkan data tentang bentuk, warna logo, dan media promosi yang akan dirancang.

Pada tahap wawancara peneliti melakukan wawancara dengan masyarakat sebagai pengguna aplikasi Jejakatua untuk mendapatkan data tentang seberapa jauh mereka mengenal UPN "Veteran" Jatim. Apa yang ada di pikiran masyarakat dalam mengenal UPN "Veteran" Jatim. Wawancara dilakukan kepada peserta UTBK 2020 yang bertempat di UPN "Veteran" Jatim, di mana para peserta adalah masyarakat yang sebelumnya tidak pernah mengunjungi UPN "Veteran" Jatim sehingga mereka butuh informasi ruang ujian. Teknik terakhir yaitu studi liteartur yakni peneliti melaksanakan kajian pustaka melalui sumber bacaan makalah, jurnal nasional, artikel offline maupun online, dan buku yang berkaitan langsung dengan perancangan logo dan identitas visual serta tentang virtual campus tour, hal ini dilakukan untuk mendapatkan data tentang pembuatan desain identitas visual yang dirancang berdasarkan rujukan teori dan referensi dari para 
pakar peneliti, perancang, maupun akademisi agar bisa menghasilkan logo yang orisinil dan memiliki nilai kebaruan.

Setelah mengumpulkan data, langkah selanjutnya menganalisis data menggunakan metode $5 \mathrm{~W}+1 \mathrm{H}$. Data dianalisis dari fenomena yang ada, hingga terkumpulnya data yang dibutuhkan lalu ditarik satu kesimpulan. Penelitian ini berfokus pada teknik analisis $5 \mathrm{~W}+1 \mathrm{H}$ untuk mendapatkan analisis permasalahan yang lengkap sehingga menghasilkan solusi yang tepat dan efektif.

Sintesis adalah kesimpulan hasil dari analisis data. Pada tahap ini saatnya peneliti menentukan objek perancangan untuk memberikan solusi terhadap permasalahan yang telah ditemukan. Proses menentukan objek perancangan didapat dari hasil analisis data yang disimpulkan dalam sintesis. Target untuk memenuhi solusi dari permasalahan yang ada sebagai berikut 1) Menghasilkan identitas visual yang mampu mencitrakan dan mengkarakterkan aplikasi Jejakatua agar mudah dikenal oleh masyarakat, 2) Menghasilkan desain logo yang merupakan bagian dari identitas visual untuk keperluan media promosi aplikasi Jejakatua, dan 3) Menghasilkan logo yang mudah diingat, kebaruan, dan memiliki masa usia yang panjang, dalam hal ini tidak mudah terkikis oleh jaman.

\subsection{Tahap Penciptaan}

Tahap penciptaan meliputi pra-produksi, produksi, dan pasca-produksi. Tahap praproduksi meliputi penyusunan konsep desain. Konsep desain terdiri dari konsep visual, konsep verbal, dan konsep media. Konsep visual meliputi ilustrasi, tipografi, warna. Sedangkan konsep verbal meliputi Bahasa yang digunakan dalam identitas visual, teknik komunikasi, cara penyampaian, kalimat yang digunakan. konsep media meliputi ukuran media, bahan media, pemilihan media promosi, dan lainnya.

Selanjutnya tahap produksi adalah tahap membuat desain untuk media identitas visual. Diawali dengan membuat beberapa alternative desain logo kemudian dipilih satu yang terbaik lalu di implementasikan ke medianya. Pemilihan final desain logo dipilih atas dasar aspek-aspek logo yang didapat dari studi literatur yang merujuk pada teori Wahyuningsih. Menurut (Wahyuningsih 2013), untuk memahami logo secara lebih komprehensif, perlu diperhatikan tabel 1 berikut ini:

Tabel 1. Aspek-aspek Logo

[Sumber : Wahyuningsih, 2013]

\begin{tabular}{|c|l|}
\hline Aspek Logo & \multicolumn{1}{c|}{ Uraian } \\
\hline Efektivitas & $\begin{array}{l}\text { Memiliki keunikan, fungsional atau mudah ditempatkan/ diatur, } \\
\text { mengikuti kaidah dasar desain, representatif }\end{array}$ \\
\hline Warna & $\begin{array}{l}\text { Lebih baik menggunakan warna yang seminimal mungkin/ spot, hindari } \\
\text { gradasi warna }\end{array}$ \\
\hline Teknik & Gunakan program vektor grafis karena bersifat fleksibel secara ukuran \\
\hline Regulasi & $\begin{array}{l}\text { Harus waspada dengan hak cipta (jangan menjiplak, menggunakan } \\
\text { gambar orang yang masih hidup, jangan memakai pilihan font spesifik } \\
\text { clip art, hindari sara, dan foto yang rumit) }\end{array}$ \\
\hline
\end{tabular}


Tahap akhir penciptaan adalah tahap pasca-produksi. Tahap ini saatnya mempublikasikan final logo ke aplikasi Jejakatua dan mempublikasikan media promosi ke Instagram dan laman resmi www.upnjatim.ac.id.

\section{HASIL DAN PEMBAHASAN}

\subsection{Hasil Pengumpulan Data}

Tahap observasi dilakukan dengan mengamati beberapa hal yang berkaitan dengan tema penelitian. Observasi pertama melakukan pengamatan pada atribut yang dipakai oleh UPN "Veteran" Jatim, atribut yang dipakai adalah seragam yang digunakan Dosen dan karyawan UPN "Veteran" Jatim dan almamater mahasiswa UPN "Veteran" Jatim. Berikut atributnya:

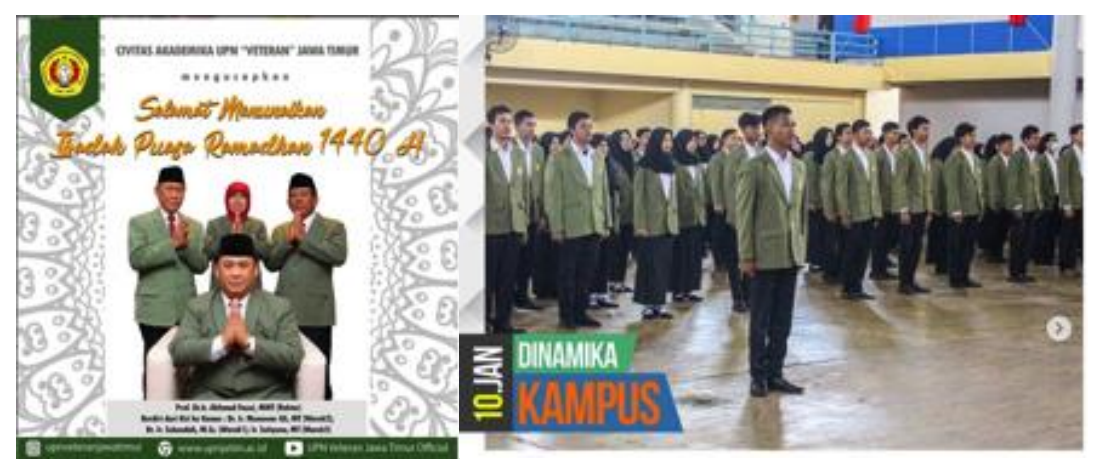

Gambar 3. Atribut UPN “Veteran” Jawa Timur

[Sumber: Instagram: @upnveteranjawatimur]

Hasil observasi dari ketiga foto atribut UPN "Veteran" Jatim yang terdiri dari seragam kerja Dosen, serta almamater mahasiswa memiliki kesamaan dalam penggunaan warna. Warna yang digunakan sebagai identitasnya adalah warna hijau. Observasi yang kedua dilakukan dengan cara mengamati logo UPN "Veteran" Jatim yang selama ini dijadikan identitas visual kampus supaya lebih mudah mengenal UPN "Veteran" Jatim.

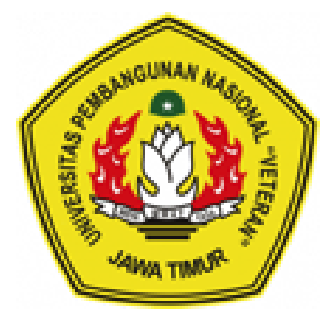

Gambar 4. Logo UPN “Veteran” Jawa Timur [Sumber : UPT, 2018]

Pengumpulan data melalui wawancara dilakukan kepada peserta UTBK 2020 yang berlokasi di UPNVJ dalam hal ini sebagai narasumber menyatakan bahwa mereka mengenal UPN "Veteran" Jatim sebagai kampus veteran yang sangat disiplin, tegas, dan menyandang sebagai kampus Bela Negara. Jika mereka mendengar kata UPN "Veteran" Jatim yang terlintas dalam benak dan pikiran mereka adalah warna hijau. Peserta UTBK 2020 mengaku mencari informasi tentang lokasi UPN “Veteran" Jatim melalui Instagram dan website www.upnjatim.ac.id. 
Studi literatur mendapatkan data berupa aplikasi Jejakatua adalah jelajah kampus virtual yang dimiliki UPN "Veteran" Jatim. UPN "Veteran" Jatim adalah sebuah institusi tempat bernaungnya sekelompok orang yang melakukan kegiatan belajar mengajar yang kental dengan pendidikan, pengetahuan, kecerdasan. Karakter tersebut hendaknya muncul dalam logo yang bisa di implementasikan dalam bentuk atau warna. Dalam hubungannya dengan logo, warna merupakan elemen yang sangat penting dalam peranannya sebagai media pengingat (Vancha 2010). Untuk penyebarluasan brandname, logo sering disebarluaskan lewat kartu nama, kop surat, amplop, map, tas, stiker, jaket, topi, payung, website, billboard, umbul-umbul, dan hampir semua permukaan yang dapat dijadikan media iklan untuk logo. Fungsi logo diantaranya adalah identitas diri (untuk membedakannya dengan identitas milik orang lain), tanda kepemilikan, untuk membedakan miliknya dengan milik orang lain, tanda jaminan kualitas, mencegah peniruan atau pembajakan (Rustan 2013).

\subsection{Investigasi dan Analisis Data}

Data selanjutnya dianalisis menggunakan $5 \mathrm{~W}+1 \mathrm{H}$ yaitu What; masalah apa yang sedang terjadi saat ini? Masalah yang terjadi adalah belum adanya identitas visual yang dimiliki aplikasi Jejakatua. Sehingga masyarakat sulit mengetahui adanya aplikasi virtual tour yang dimiliki UPN "Veteran" Jatim. Who; siapa target audiensnya? Target audiensnya adalah seluruh stakeholder seperti mahasiswa baru, calon mitra, ataupun kolega dari luar kota, luar daerah atau bahkan luar negeri yang berkaitan dengan informasi sarana dan prasarana Kampus. Berdasarkan hasil studi literature, identitas yang mudah dikenal masyarakat terhadap UPN "Veteran" Jatim adalah sebagai kampus veteran yang berkarakter Bela Negara. Dan yang terlintas dalam benak dan pikiran masyarakat tentang UPN "Veteran" Jatim adalah warna hijau. Atribut yang digunakan UPN "Veteran" Jatim juga mayoritas menggunakan warna hijau. Sejauh ini identitas visual yang dimiliki UPN "Veteran" Jatim sebagai media pengenal kampus adalah logo. Logo Aplikasi Jejakatua harus bisa mempresentasikan sebuah aplikasi petunjuk lokasi UPN "Veteran" Jatim dengan cara mewujudkannya dalam sebuah bentuk atau warna. Where; dimana permasalahan tersebut terjadi? Permasalahan ini terjadi di saat aplikasi Jejakatua memperkenalkan diri kepada masyarakat. Aplikasi Jejakatua membutuhkan media yang bisa mewakili dirinya untuk dikenal dan diketahui masyarakat. Sehingga media tersebut bisa dipublikasikan di media sosial milik akun resmi UPN “Veteran" Jatim seperti Instagram dan laman resmi www.upnjatim.ac.id.

Selanjutnya When; kapan masalah ini terjadi? Permasalahan ini terjadi ketika target audiens hendak mengunjungi UPN “Veteran" Jatim, mereka mengaku kesusahan dalam mengetahui detail lokasi yang ditunjukkan pada website UPN "Veteran" Jatim. Karena gambar lokasi yang ditunjukkan pada website kurang jelas dalam menggambarkan lokasi, hanya gambar garis, bukan foto. Sehingga identitas visual aplikasi Jejakatua diperlukan saat melakukan promosi. Agar aplikasi Jejakatua mudah dikenal dan diingat oleh target audiens. Why; apa alasan terjadinya permasalahan ini? Beberapa faktor penyebab munculnya pentingya identitas visual aplikasi Jejakatua: (1) sebagai identitas diri aplikasi Jejakatua agar mudah dikenal dan diingat target audiens serta membedakannya dengan identitas milik orang lain; (2) sebagai media promosi aplikasi 
Jejakatua; (3) tanda jaminan kualitas; (4) mencegah peniruan atau pembajakan. Terakhir Who; bagaimana solusinya untuk menyelesaikan masalah tersebut? Solusinya adalah membuat identitas visual aplikasi Jejakatua agar mudah dikenal dan diingat masyarakat dan mencegah peniruan atau pembajakan. Identitas visual tersebut berupa logo yang bisa diimplementasikan pada media stationary atau merchandise yang dibutuhkan target audiens seperti kaos, stiker, topi, tas, dan lain-lain.

\subsection{Sintesis}

Kesimpulan analisis $5 \mathrm{~W}+1 \mathrm{H}$ terhimpun dalam sintesis. Sintesis didapatkan beberapa poin, dintaranya: 1) Identitas visual Aplikasi Jejakatua berupa logo. 2) Logo aplikasi Jejakatua mengandung karakter/identitas UPN "Veteran" Jatim sebagai pemiliknya. Warna kuning pada logo UPN "Veteran" Jatim muncul dalam logo alpikasi Jejakatua, warna hijau yang sering muncul dilingkungan kampus UPN "Veteran" Jatim sebagai seragam dan almamater bagi Dosen, karyawan, dan mahasiswa. 3) Tanda lokasi sebagai bentuk perwakilan dari karakter jenis aplikasi yang dibuat. 4) Bentuk logo yang tegas seperti karakter Bela Negara dan kampus veteran yang selama ini tertanam dibenak masyarakat tentang UPN "Veteran" Jatim. 5) Karakter sebuah tempat pendidikan harus muncul dalam logo. 6) Logo Aplikasi Jejakatua diimplementasikan pada media promosi. 7) Media stationary dan merchandise yang sering digunakan target audiens untuk media promosi Aplikasi Jejakatua. 8) Logo Aplikasi Jejakatua dipublikasikan melalui Instagram dan laman resmi UPN "Veteran" Jatim.

\subsection{Tahap Pra-Produksi}

Konsep Verbal berupa logo aplikasi Jejakatua menggunakan bahasa Indonesia agar lebih mudah dipahami oleh masyarakat. Sehingga masyarakat mudah dalam memahami informasi yang disampaikan. Nama aplikasi adalah "JEJAKATUA" yang merupakan singkatan dari Jejalah Kampus Virtual. Nama aplikasi disingkat supaya mudah di ingat dengan menggunakan nama yang unik. Bagian bawah teks Jejakatua terdapat tagline sekaligus kepanjangan dari nama aplikasi supaya masyarakat tahu makna Jejakatua.

Konsep Visual berupa logo aplikasi Jejakatua dibuat berdasarkan hasil sintesis dan harus bisa memenuhi aspek-aspek dalam pembuatan logo. Berikut konsep visual logo Aplikasi Jejakatua: Ilustrasi yang dipakai dalam logo Aplikasi Jejakatua dibuat sederhana hingga membentuk pictogram supaya logo readibility, menarik, dan mudah diingat. Bentuk logo terkesan tegas untuk memunculkan karakter Bela Negara dan Veteran. Tanda lokasi sebagai bentuk perwakilan dari karakter jenis aplikasi yang dibuat. Topi toga diimplementasikan dalam logo sebagai identitas sebuah aplikasi pendidikan tinggi. Warna kuning pada logo UPN "Veteran" Jatim dipakai dalam logo alpikasi Jejakatua untuk memunculkan identitas UPNVJ. Warna hijau yang sering muncul dilingkungan kampus UPN "Veteran" Jatim sebagai seragam dan almamater bagi dosen, karyawan, dan mahasiswa diterapkan dalam logo Aplikasi Jejakatua agar masyarakat semakin mudah mengenal aplikasinya. Warna merah digunakan agar menonjol dibandingkan gambar lainnya yang ada di sekeliling logo dan juga sebagai pusat perhatian masyarakat agar penglihatannya tertuju pada logo. Karakter tegas/kuat/berenergi/pemimpin juga 
bisa di implementasikan pada warna merah. Jenis tipografi yang dipakai adalah sanserif dan menggunakan huruf lowercase agar logogram lebih menonjol.

Konsep Media yaitu desain logo Aplikasi Jejakatua yang telah dibuat diimplementasikan pada media promosi. Pemilihan media promosi berdasarkan tingkat kebutuhan target audiens terhadap benda-benda yang sering mereka gunakan. Berdasarkan hasil observasi, analisis, dan sintesis didapatkan bahwa media promosinya adalah totebag, kaos, topi, stiker, gantungan kunci, pena, notebook.

\subsection{Tahap Produksi}

Tahap pertama produksi berupa tahap alternatif desain membuat 3 alternatif desain aplikasi Jejakatua yang mengandung aspek-aspek logo. Desain logo yang paling memenuhi aspek logo akan dipilih menjadi final desain. Berikut ini adalah tabel alternatif desain logo aplikasi Jejakatua.

Tabel 2. Alternatif Desain Logo Aplikasi Jejakatua.

[Sumber: Dokumentasi Tim Peneliti]

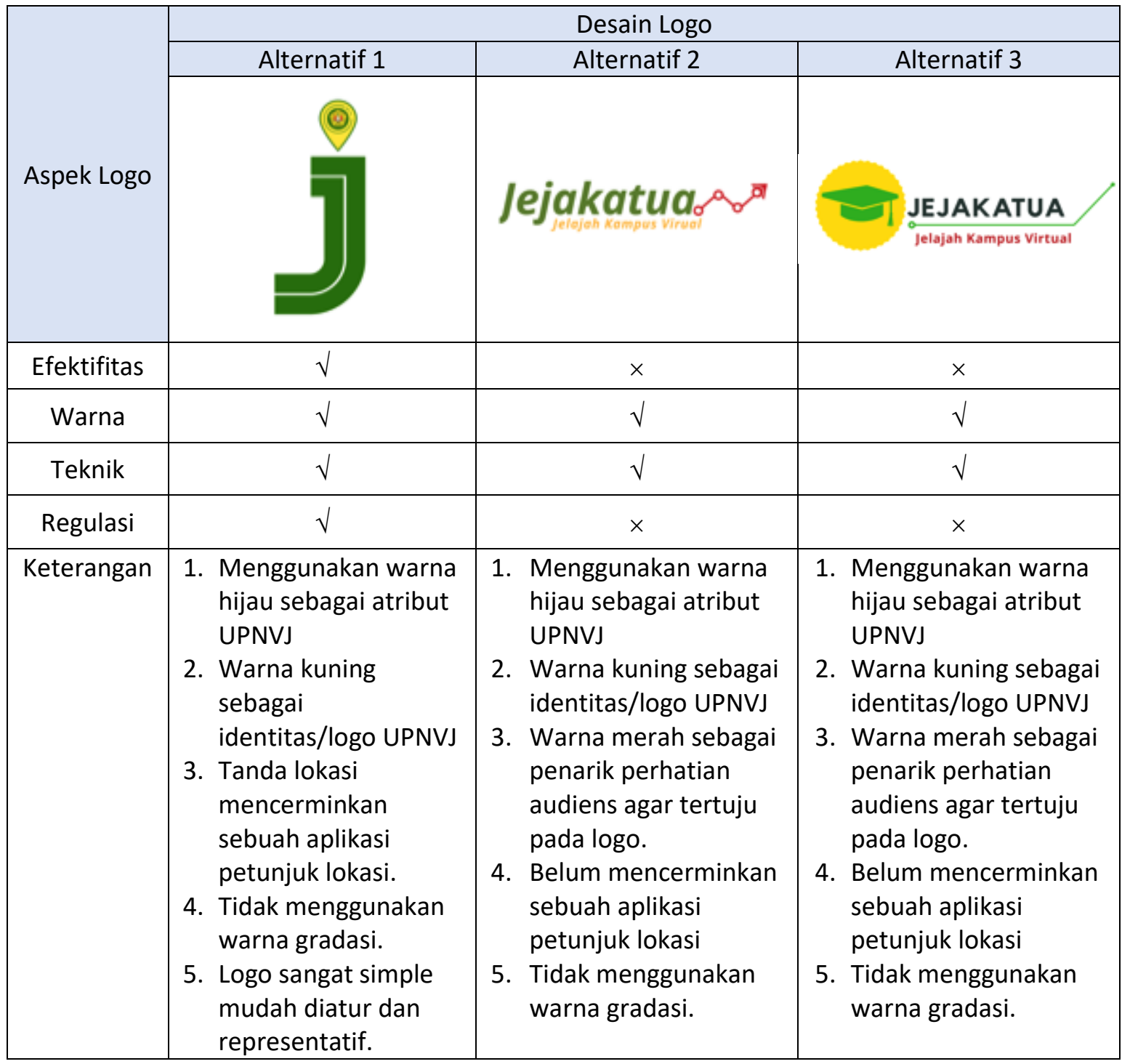




\begin{tabular}{|c|c|c|c|}
\hline & $\begin{array}{l}\text { 6. Gambar dan huruf } \\
\text { tidak menggunakan } \\
\text { klipart. } \\
\text { 7. Tidak menggunakan } \\
\text { gambar orang yang } \\
\text { masih hidup dan } \\
\text { tidak mengandung } \\
\text { SARA. }\end{array}$ & $\begin{array}{l}\text { 6. Logo tidak mudah } \\
\text { diatur dan tidak } \\
\text { representatif karena } \\
\text { ada garis tipis } \\
\text { sehingga tidak } \\
\text { kelihatan jika } \\
\text { diimplementasikan } \\
\text { pada background } \\
\text { gelap atau ramai. } \\
\text { 7. Tidak menggunakan } \\
\text { gambar orang yang } \\
\text { masih hidup dan tidak } \\
\text { mengandung SARA. }\end{array}$ & $\begin{array}{l}\text { 6. Logo tidak mudah } \\
\text { diatur dan tidak } \\
\text { representatif karena } \\
\text { warna kuning terlalu } \\
\text { muda sehingga jika } \\
\text { diimplementasikan } \\
\text { pada background } \\
\text { terang atau ramai } \\
\text { tidak terlihat/tidak } \\
\text { readible. } \\
\text { 7. Gambar jaringan } \\
\text { menggunakan klipart. } \\
\text { 8. Tidak menggunakan } \\
\text { gambar orang yang } \\
\text { masih hidup dan tidak } \\
\text { mengandung SARA. }\end{array}$ \\
\hline
\end{tabular}

Selanjutnya final desain dipilih. Desain logo terpilih adalah logo alternatif 1 pada tabel 2 yang paling memenuhi aspek logo. Gambar 5 memberikan penjelasan mengenai makna yang diperoleh secara anatomi dan histori terkait final logo yang dipilih oleh tim peneliti. Juga diperkuat secara filosofi pada tabel 3, dimana final logo Jejakatua bukan sekedarnya dibuat melainkan memiliki nilai-niliai karakteritik Kampus.

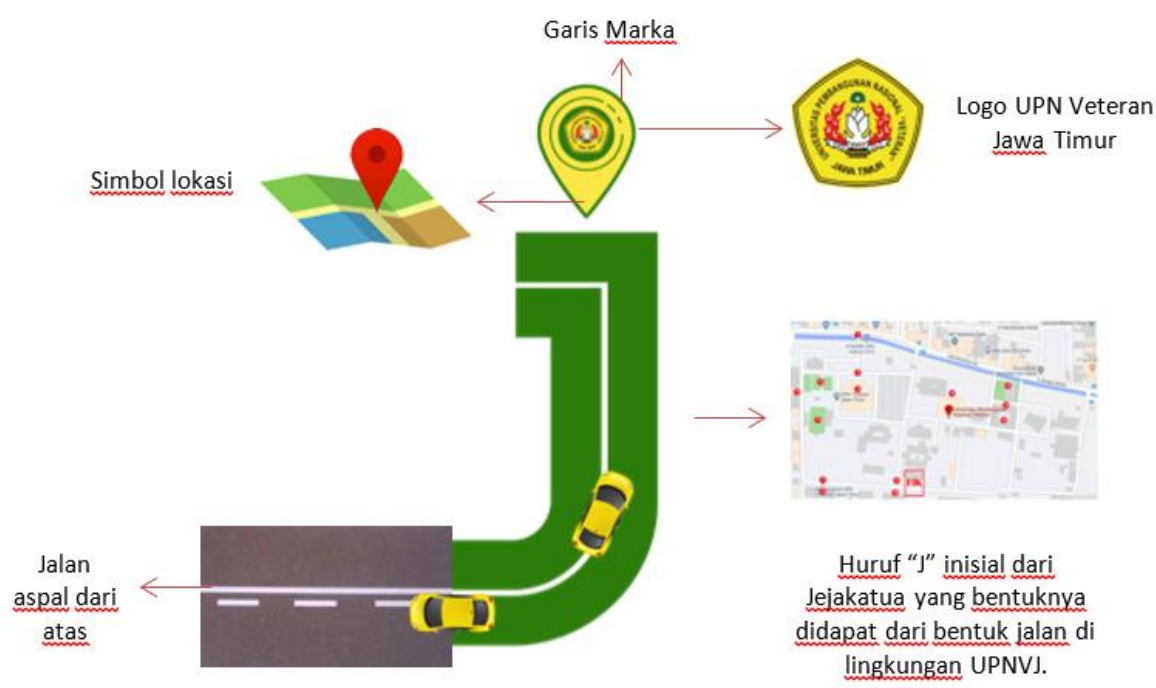

Gambar 5. Anatomi Logo Jejakatua [Sumber: Dokumentasi Tim Peneliti] 
Tabel 3. Filosofi Logo Jejakatua

[Sumber: Dokumentasi Tim Peneliti]

\begin{tabular}{|c|c|}
\hline Logo & Filosofi \\
\hline & $\begin{array}{l}\text { Huruf "J" merupakan singkatan dari Jejakatua. Menggunakan huruf Colo Pro. } \\
\text { Bentuk jalan aspal yang terlihat dari sisi atas pada huruf "J" merepresentasikan } \\
\text { sebuah logo aplikasi perjalanan menuju lokasi. }\end{array}$ \\
\hline & tanda lokasi, mencerminkan aplikasi yang berfungsi sebagai petunjuk lokasi. \\
\hline & $\begin{array}{l}\text { Logo UPN “Veteran" Jatim merepresentasikan sebuah aplikasi petunjuk lokasi } \\
\text { milik UPN “Veteran" Jatim. }\end{array}$ \\
\hline $\begin{array}{l}\text { Warna } \\
\text { Kuning }\end{array}$ & $\begin{array}{l}\text { Sinar matahari, gembira, bahagia, tanah, optimis, cerdas, idealisme, kaya (emas), } \\
\text { musim panas, harapan, udara, liberalisme, pengecut, sakit (karantina), takut, } \\
\text { bahaya, tidak jujur, serakah, lemah, feminin, bergaul, persahabatan, zodiak } \\
\text { gemini, taurus, leo, april, bulan September, kematian (abad pertengahan), } \\
\text { perkabungan (Mesir), berani (Jepang), Tuhan (kuning emas) (Rustan 2013). } \\
\text { Selain sebagai identitas logo UPN "Veteran" Jatim, warna kuning pada logo } \\
\text { aplikasi Jejakatua juga menunjukkan sebuah harapan anak didik (mahasiswa) } \\
\text { dalam menuntut ilmu. }\end{array}$ \\
\hline $\begin{array}{l}\text { Warna } \\
\text { Hijau }\end{array}$ & $\begin{array}{l}\text { Hijau: Kecerdasan tinggi, alam, musim semi, kesuburan, masa muda, lingkungan } \\
\text { hidup, kekayaan, uang (Amerika), nasib baik, giat, murah hati, pergi, rumput, } \\
\text { agresi, dingin, cemburu, malu (Cina), sakit, rakus, narkoba, korupsi (Afrika Utara), } \\
\text { abadi, udara, tanah, tulus, zodiak cancer, pembaruan, pertumbuhan, kesehatan, } \\
\text { bulan Agustus, keseimbangan, harmoni, stabil, tenang, kreatif, Islam (Rustan } \\
\text { 2013). Warna hijau menggambarkan atribut yang dipakai UPN "Veteran" Jatim. } \\
\text { Selain itu, warna hijau pada logo Aplikasi Jejakatua juga memiliki makna } \\
\text { kecerdasan yang berhubungan dengan dunia pendidikan. }\end{array}$ \\
\hline
\end{tabular}

Sebagaimana dalam kutipan logo Universitas Telkom, logo sekunder digunakan apabila penampilan logo primer kurang maksimal keterlihatannya, atau kurang cocok. Misalnya, pada pengaplikasian luar ruang, untuk mencerminkan kesan premium, elegan, dan/atau untuk penggunaan pada bidang yang material dasarnya atau warnanya gelap. Logo Sekunder dapat digunakan sebagai variasi tampilan setelah penggunaan logo primer dalam suatu program atau dalam satu lingkungan yang sama. Sebagai penekanannya, logo primer tetap menjadi prioritas utama untuk diaplikasikan. (MFc, 2017).

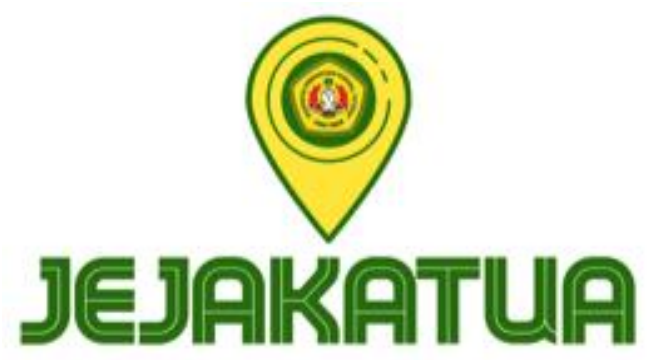

Gambar 6. Logo Sekunder Jejakatua [Sumber: Dokumentasi Tim Peneliti] 
Sebagaimana terlihat pada gambar 6, terdapat logo sekunder Jejakatua yang secara desain dan filosofi logo sekunder dan logo primer memiliki konsep dan anatomi yang sama, hanya berbeda pada layout saja. Logo primer bentuknya vertikal, sedangkan logo sekunder di desain dengan bentuk horisontal agar logo Aplikasi Jejakatua dapat diimplementasikan di segala bidang media.

Setiap kegiatan promosi membutuhkan media dalam kegiatan penyampaian kepada konsumen. Media yang sering digunakan untuk promosi adalah media cetak dan elektronik. Media cetak misalnya surat kabar dan majalah, merchandise, stationary, sedangkan media elektronik misalnya televisi, radio dan lain-lain. Bahan dan bentuk media promosi bermacam-macam, bisa diletakkan di meja, digantung, pena, traveling bag, map, dan lain-lain (Harsono, 2016). Sebagai implementasi desain gambar berikut ini adalah media promosi cetak berupa merchandise yang promosikan melalui website UPN Veteran Jatim.

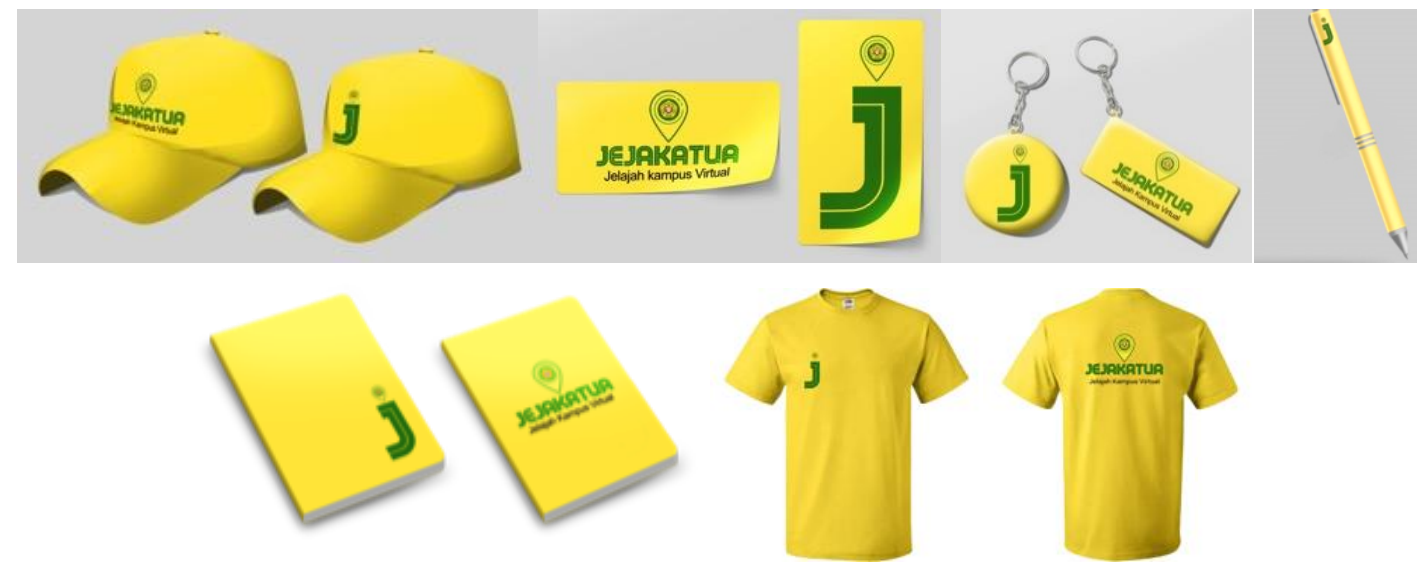

Gambar 7. Implementasi Logo dalam Media-media Promosi [Sumber: Dokumentasi Tim Peneliti]

Media promosi berupa merchandise dan alat tulis dipilih berdasarkan observasi yang telah dilakukan terhadap mahasiswa UPN Veteran Jatim. Hasil observasi yaitu media yang sering digunakan oleh mahasiswa adalah topi, stiker, gantungan kunci, pena, notebook, dan kaos.

\subsection{Pasca Produksi}

Tahap pasca produksi adalah publikasi desain logo aplikasi Jejakatua yang diimplementasikan di aplikasi Jejakatua. Serta publikasi media promosi di laman resmi www.upnjatim.ac.id dan instagram. Social media menurut Van Dijk dalam Zuhri (2019:27) adalah platform media yang memfokuskan pada eksistensi pengguna yang memfasilitasi mereka dalam beraktifitas maupun berkolaborasi. Karena itu, social media dapat dilihat sebagai medium (fasilitator) online yang menguatkan hubungan antar pengguna sekaligus sebagai sebuah ikatan sosial. Dari teori tersebut dapat disimpulkan bahwa social media dapat dimanfaatkan sebagai media promosi yang tepat, khususnya Instagram yang keberadaannya saat ini sangat dekat dengan masyarakat. 
Sebagaimana yang telah tersaji pada gambar 14 dan 15, implementasi logo aplikasi Jejakatua dilakukan pada sosial media Instagram sekaligus diimplementasikan juga pada situs web resmi UPN "Veteran" Jatim. Memperhatikan pasca-produksi desain visual produk artinya sama dengan memperhatikan keberlangsungan siklus produk yang sustainability sehingga mampu untuk menggambarkan citra dan karakter Kampus. Menurut Ardhi (2013:63) menyatakan "media website bisa berisi tulisan, gambar, animasi, lagu hingga video. Dengan perkembangannya yang sangat pessat saat ini, bebabagai promosi bisa dilakukan dengan website".

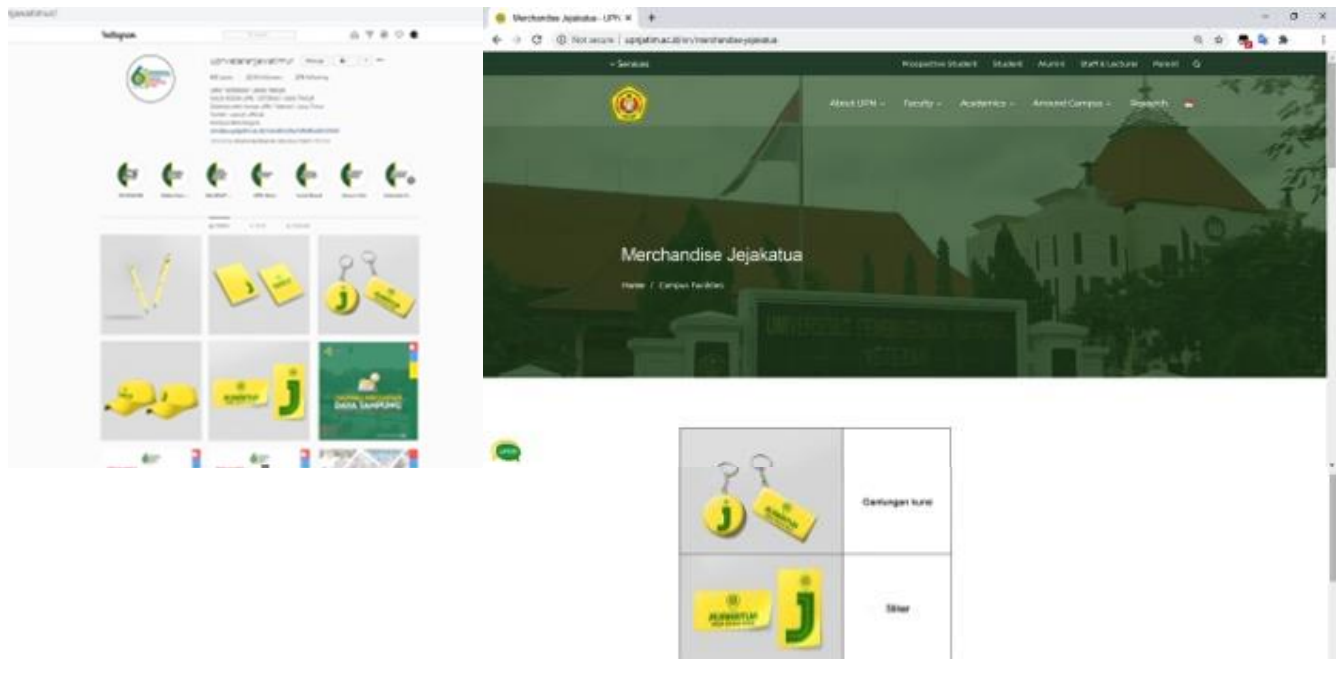

Gambar 8. Implementasi Media Promosi di Instagram (kiri) Website (kanan) UPN “Veteran” Jatim [Sumber: Dokumentasi Tim Peneliti]

\section{KESIMPULAN}

Aplikasi Jejakatua adalah aplikasi virtual tour lingkungan UPN "Veteran" Jatim. Melalui aplikasi Jejakatua maka masyarakat semakin mudah mengunjungi kampus UPN "Veteran" Jawa Timur melalui virtual tour dan memiliki beberapa manfaat seperti jaringan kampus bisa berkembang, calon mahasiswa baru, calon mitra, ataupun kolega dari luar kota, luar daerah atau bahkan luar negeri lebih mudah untuk mengetahui gambaran kampus UPN "Veteran" Jatim, sehingga jauhnya jarak dan biaya sudah tidak lagi menjadi kendala untuk melihat atau menuju kampus UPN "Veteran" Jawa Timur. Aplikasi Jejakatua diterapkan pada website resmi UPN "Veteran" Jawa Timur sehingga banyak masyarakat yang mengaksesnya, dengan adanya identitas visual maka aplikasi Jejakatua bisa dibedakan dengan identitas aplikasi lainnya. Aplikasi Jejakatua memiliki tanda kepemilikan untuk membedakan miliknya dengan milik orang lain. Logo Jejakatua dirancang sesuai aspek-aspek pembuatan logo yang meliputi tampak di tabel 4 . 
Tabel 4. Implikasi IImiah Logo Jejakatua

[Sumber: Dokumentasi Tim Peneliti]

\begin{tabular}{|c|l|}
\hline Aspek Logo & \multicolumn{1}{c|}{ Implikasi Ilmiah } \\
\hline Efektivitas & $\begin{array}{l}\text { - Memiliki keunikan, yakni belum pernah ada desain logo yang } \\
\text { menyerupai. } \\
\text { - Fungsional atau mudah ditempatkan/ diatur, mengikuti kaidah dasar } \\
\text { desain. }\end{array}$ \\
\hline Warna & $\begin{array}{l}\text { Representatif, sesuai dengan karakter dan ciri khas UPN Veteran } \\
\text { Jawa Timur. }\end{array}$ \\
\hline Teknik & $\begin{array}{l}\text { Menggunakan vector, sehingga secara visual mudah dipahami dan } \\
\text { readable. }\end{array}$ \\
\hline Regulasi & $\begin{array}{l}\text { - Riset logo yang mendalam, sehingga terjamin orisinalitasnya. } \\
\text { Tidak menggunakan gambar orang yang masih hidup, tidak } \\
\text { menggunakan clip art, tidak mengandung sara dan tidak } \\
\text { menggunakan foto. }\end{array}$ \\
\hline
\end{tabular}

Semua aspek logo didapat dari pengumpulan data observasi, wawancara dan studi literatur. Logo aplikasi Jejakatua juga berfungsi sebagai tanda jaminan kualitas, mencegah peniruan atau pembajakan. Konsep logo aplikasi Jejakatua dirancang dengan merujuk pada karakter/identitas UPN "Veteran" Jatim sebagai institusi yang menaunginya. Seperti penggunaan warna hijau mewakili atribut UPNVJ, warna kuning mewakili logo UPNVJ, bentuk yang tegas mencirikan karakter kampus Bela Negara, tanda lokasi sebagai gambaran logo aplikasi lokasi, dan sebagainya. Sehingga logo aplikasi Jejakatua memiliki kebaruan dan desain kekinian yang berbeda dengan desain logo lainnya sehingga logo Jejakatua mampu membangun citra agar mudah diingat dan dikenali. Logo diimplementasikan pada aplikasi Jejakatua dan media promosi seperti stationary dan merchandise. Kemudian media promosi dipublikasikan di laman resmi www.upnjatim.ac.id dan instagram. Selanjutnya logo Aplikasi Jejakatua didaftarkan hak paten agar mendapatkan legalitas.

Saran untuk penelitian selanjutnya adalah mengukur efektifitas adanya logo Jejakatua sebagai identitas visual dan media promosi yang telah dipublikasikan kepada masyarakat. Pengukuran tersebut meliputi: 1) Seberapa besar logo Jejakatua dapat merepresentasikan karakter aplikasi jejakatua. 2) Seberapa besar identitas visual Jejakatua dapat merepresentasikan karakter aplikasi Jejakatua. 3) Seberapa banyak peningkatan jumlah masyarakat yang menggunakan aplikasi Jejakatua setelah adanya logo dan identitas visual. 4) Seberapa banyak jumlah masyarakat yang pernah melihat media promosi Jejakatua.

\section{DAFTAR PUSTAKA}

Agustin, S. M., \& Putra, S. J. (2020). Perancangan Identitas Visual dan User Interface Aplikasi JUALOMBOK. JTIM : Jurnal Teknologi Informasi Dan Multimedia, 2(1), 50-58. 
Anwar, Muhammad Syaiful. (2018). "Rancang Bangun Aplikasi Jelajah Virtual Panorama Berbasis Web Pada Universitas Pgri Madiun." Journal Of Computer And Information Technology Vol. 2, No:12-15.

Aprillia, Ariesya; Nonie Magdalena. (2018). "Pengukuran Kualitas Layanan dalam Bidang Pendidikan Tinggi." Manajemen Maranatha 18:11-22.

Colasante, Meg. (2011). Nicola Building Virtual Tour; Considering Simulation in the Equity of Experience Concept.

Harsono. (2016). Perancangan Merchandise sebagai Media Promosi Tempat Wisata Kolam Renang Marina Semarang, 3.

Hendrayana, A. S. (2014). "Pengaruh Kualitas Pelayanan Dan Nilai Pelanggan Terhadap Citra Serta Dampaknya Pada Loyalitas Mahasiswa." Riset Manajemen 3(2).

Maymun, A. Z., \& Swasty, W. (2018). Identitas Visual Dan Penerapannya Pada Signage Untuk Kawasan Wisata Edukasi. Serat Rupa Journal of Design, 2(1), 01.

Mfc. (2017). Inilah Berbagai Varian Logo Telkom University. studentstelkomuniversity.com. Retrieved 15 December 2020, from https://studentstelkomuniversity.com/inilah-berbagai-varian-logo-telkomuniversity/2/

Rustan, Surianto. (2013). Mendesain Logo. 4th ed. Jakarta: PT. Gramedia Pustaka Utama. Septiningtyas, A., \& Soewardikoen, D. W. (2018). Perancangan Identitas Visual Dan Promosi Sasirangan Banjarbaru. Demandia:Desain Komunikasi Visual, Manajemen Desain Dan Periklanan.

Sugiyono. (2018). "Metode Penelitian Kuantitatif,Kualitatif Dan R\&D." in ke-26.

UPN. (2018). "Sejarah UPN 'Veteran' Jawa Timur." Sejarah.

UPT, TIK. (2018). "UPN 'Veteran' Jawa Timur." UPN "Veteran" Jawa Timur.

Vancha, Tony. (2010). "Teori Logo Beserta Elemennya." Jurnal Unikom 10:14.

Wahyuningsih, Sri. (2013). Desain Komunikasi Visual. 1st ed. Madura: UTM Press.

Yusantiar, Renta, \& Didit Widiatmoko Soewardikoen. (2018). "Perancangan Identitas Visual Untuk Promosi Pariwisata Kabupaten Rembang." ANDHARUPA: Jurnal Desain Komunikasi Visual \& Multimedia 4(02):207-20.

Zuhri, A.M., \& Lidya, C. (2019). Pemanfaatan Media Sosial Instagram Sebagai Media Promosi Library Based Community (Studi Kasus Komunitas Perpustakaan Jalanan Solo @Koperjas). Jurnal Ilmu Perpustakaan, 27. 